\title{
PENSAR E PROPOR A ECOCIDADANIA DESDE A FORMAÇÃO DE PROFESSORES DE GEOGRAFIA: TECENDO DIÁLOGOS PARA UMA ESCOLA REFLEXIVA
}

\section{Thinking and proposing ecocitizenship from the formation of teachers of Geography: weaving dialogues for a reflective school}

\author{
Lucas Antônio Viana Botêlho \\ Doutorando no Programa de Pós-graduação em Geografia - PPGEO/UFPE \\ lucasviana.botelho@gmail.com
}

Professor do curso de graduação em Geografia e do Programa de Pós-graduação em Geografia PPGEO/UFPE

Francisco Kennedy Silva dos Santos kennedyufpe@gmail.com

Artigo enviado para publicação em 07/08/2018 e aceito em 24/09/2018

DOI: $10.12957 /$ tamoios.2018.36571

\section{RESUMO}

A ecocidadania emerge no cenário em que se faz emergencial pensar possibilidades de reconfiguração da relação entre sociedade e natureza. Diante disto, esta perspectiva propõe trilhar caminhos formativos, desde o chão da escola às práticas sociais cotidianas, que conduzam os sujeitos a (re)pensar a relação estabelecida entre si e com o lugar de vida, de modo que possam confeccionar ações pautadas no diálogo e que objetivem o equilíbrio e o bem estar socioambiental. Objetiva-se, portanto, argumentar possibilidades e caminhos da ecocidadania, desde a formação inicial e continuada dos professores de Geografia até as práticas em sala de aula, mediando aproximações e convergências entre Geografia e Educação Ambiental, criando espaço para os saberes cotidianos na sala de aula. Para tanto, faz-se um entretecimento de referenciais que compreendam uma argumentação crítico-reflexiva, apontando diálogos emergentes no processo de ensino-aprendizagem contemporâneo.

Palavras-chave: Ecocidadania; Ensino de Geografia; Formação de professores.

\begin{abstract}
Ecocityzenship emerges in the scenario in which it becomes urgent to think of possibilities of reconfiguration of the relationship between society and nature. In view of this, this perspective proposes to guide formative paths, from the ground of the school to daily social practices, that lead the subjects to (re) think the established relation between themselves and the place of life, so that they can make actions guided by the dialogue and that aim at the balance and social and environmental well-being. The objective is, therefore, to argue the possibilities and paths of ecocityzenship, from the initial and continuous formation of the Geography teachers to the practices in the classroom, mediating approximations and convergences between Geography and Environmental Education, creating space for everyday knowledge in the classroom. In order to do so, a series of references is made that understand a critical-reflexive argument, pointing to emerging dialogues in the contemporary teaching-learning process.
\end{abstract}

Keywords: Ecocitizenship; Geography teaching; Teacher training. 


\section{INTRODUÇÃO}

Diante de um cenário em que a crise ambiental toma proporções cada vez maiores e suas consequências se faz sentir, cada vez mais, sobre os diversos setores da sociedade, é necessário repensar atitudes e posturas que nos trouxeram até o presente momento. Os efeitos dos avanços significativos da crise ambiental trazem desequilíbrios e acirram o desenvolvimento de problemáticas na interface sociedade e natureza. A incoerência e dissimetria entre legislação, ação política e ação social tornam evidente a existência de trabalhos pormenorizados e focados em questões específicas, ao invés de abarcar fenômenos mais amplos e que são os verdadeiros condutores dos fenômenos em menor escala.

Logicamente, as ações no campo social, conduzidas pelos sujeitos que trafegam e vivenciam cotidianamente os espaços, são concentradas nos lugares onde a relação de pertencimento e vida é concretizado e balizado também pela compreensão de quais são as necessidades desses sujeitos e lugares, como salienta Loureiro (2003). No entanto, a legislação e a ação política devem tornar estas ações condutores de ações mais amplas e que possibilitem processos transformadores de realidades de cenários mais específicos para cenários mais amplos, como, por exemplo, comunidades e bairros até a cidade como um todo.

A escola, de acordo com Alarcão (2001), é o espaço de ações que possibilita atingir a sociedade e emplacar ações efetivas em torno das necessidades comunitárias, as quais se dispersam por todo o tecido social. No entanto, é preciso afirmar que a escola não é o único espaço dotado de tal capacidade, mas detém uma grande potência, pois é evidente que as novas gerações que nela aprendem a ler e agir no mundo podem ser precursoras de uma revolução social, que também é ambiental, econômica, política e cultural.

O ensinar com a Geografia (COUTO, 2010) mediando leituras de mundo, que vão desde o lugar de vida ao mundo globalizado, encontra-se como um dos mais importantes e desafiadores fios condutores do processo de aprendizagem e construção de uma cidadania transformadora, que atua na reconfiguração do projeto societário. A apregoada formação cidadã não consegue se materializar de maneira que os sujeitos se tornem ativos e movimentem-se no sentido de uma inserção social mediada pelo diálogo entre os saberes cotidianos e os saberes científicos. Retrato este que corrobora com a educação clichê (FERRAÇO, 2015), permeada por uma lógica aplicacionista, disciplinarizante e silenciadora de saberes outros, que não aqueles previstos nos roteiros engessados das práticas pedagógicas.

Deste modo, vislumbra-se na formação de professores de Geografia a inserção de um diálogo que busque convergências entre cotidiano e formação cidadã, sobretudo a partir da perspectiva da ecocidadania, que se apresenta como caminho para superar as rupturas e descontinuidades entre o ensino da Geografia Humana e da Geografia Física, propondo, neste sentido, ações enviesadas por temáticas que propõem e dispõem de elementos que oportunizem uma aprendizagem socioambiental, uma aprendizagem que nossos tempos precisam.

Tal escrito objetiva argumentar as possibilidades e caminhos da ecocidadania, desde a formação inicial dos professores de Geografia até as práticas em sala de aula, mediando aproximações e convergências entre Geografia e Educação Ambiental. Para tanto, faz-se um entretecimento de referenciais que compreendam uma argumentação crítico-reflexiva, apontando diálogos emergentes no processo de ensino-aprendizagem contemporâneo.

\section{UMA ESCOLA REFLEXIVA EM MEIO A DIÁLOGOS EMERGENTES}

Ao longo do processo de construção da escola, que existe hoje, variados fatores incidiram sobre a prática pedagógica que a faz, que a identifica e que a particulariza. Desde práticas calcadas por uma racionalidade técnica, que instrumentaliza o saber ao passo em que o disciplina e o compartimenta, até práticas que se justificam por intermédio de uma 
racionalidade comunicativa, permeada por posturas pedagógicas e movimentos de construção de saber de forma crítica e reflexiva, problematizando a realidade. Neste sentido, inúmeras perspectivas vivem e convivem em seus muros, salas, corredores e nas intenções e ações de seus sujeitos.

É necessário compreender como se dão os movimentos de convergência e cisalhamento entre cada perspectiva, de modo a não apenas mapeá-las, mas mergulhar na seara de dimensões que são construídas a partir de cada uma delas e das interfaces entre elas. Bizelli (2015) afirma que a contemporaneidade do processo educativo carrega consigo outro movimento, o movimento de libertação de perspectivas únicas e que centralizavam sujeitos específicos, como o professor, ao passo em que silenciava outros, permitindo uma escola que pensava a si própria e se deixa ser pensada.

Alarcão (2001) sugere a necessidade de pensar uma escola que mergulha em um movimento de ruptura com elementos que, em seu cerne, centralizam e transformam o professor em transmissor de conteúdos, ou estruturas de saber normativas, que em nada dialogam com o cotidiano e as experiências e percepções dos sujeitos da aprendizagem, como frisa Ferraço (2015). Ou como expressa Girotto (2017), a lógica aplicacionista de ensino é estruturante e estruturada por um processo de ensino e aprendizagem que não caminha em direção a outros saberes, tais como os saberes da vida, mas fecha-se em torno de si mesma e elege a escola como o único espaço de se aprender a ler e discernir o mundo. Quando, na verdade, a sociedade do conhecimento, de acordo com Libâneo (2001), traz consigo um movimento que põe em xeque a eficácia da escola no aprendizado do aluno e questiona a ação do professor, culpando-o, muitas vezes, pelo fracasso escolar e por não atingir as metas estabelecidas como parâmetros reguladores de qualidade, consideradas marcas de uma educação constituída por princípios neoliberais.

Diante de tais expostos, a escola continua ocupando um lugar questionado, que ainda permanece no campo da ausência de uma busca de si própria, enquanto busca dialogar com questões emergenciais destes tempos. Daí a importância de existir um pensamento crítico, enviesado por um movimento de reflexão crítico-social, que permeia as diversas questões que estão em pleno movimento de ascendência na pauta dos movimentos sociais contemporâneos e que alimenta uma razão sensível, uma racionalidade sensível (FRAGA, 2016).

Jacobi (2005) mergulha num diálogo em que apresenta os caminhos de construção possível dessa forma de pensar a escola e suas práticas, a partir do papel da reflexividade como estratégia para formular uma "educação para a cidadania" (p. 243). Nesta mesma direção, mas sem perder o foco do papel e da relevância da escola na formação social dos indivíduos, Alarcão (2001) salienta que a escola é "lugar" (p. 16), a edificação e não somente a edificação; é "contexto" (p. 17), realidade vivenciada e multifacetada; é "tempo" (p. 18), tempo de saberaprender, de saber-fazer, de saber-ser.

A reflexão é condutora de uma educação transformadora que pronuncia a si mesma, sendo seus conhecimentos situados no campo das diversas disciplinas, tornando possível uma mediação pedagógica na qual os sujeitos se pronunciem, que suas falas sejam alinhadas pela escuta atenta e ativa do outro, como propõe Freire (1997). Ou seja, uma aprendizagem dialógica. E é neste momento que emergem questões além dos muros da escola, como questões ligadas ao meio ambiente, identidade de gênero e sexualidade, multiculturalidade, étnico-racial, política e democrática. Muitas destas estão presentes na cotidianidade dos alunos, mas nem sempre presentes na sala de aula.

Burlar práticas que tomam os conhecimentos legitimados por uma racionalidade técnica, de acordo com Ferraço (2015), perpassa pela capacidade de o professor pensar como deseja mediar as possibilidades de aprendizagem e de como é possível trazer à tona elementos que não estão previstos como, por exemplo, no livro didático e nos materiais de apoio. Significa dizer que a prática não responde por si, mas a formação responde por ela, ao passo em que a 
prática leva ao refinamento experiencial da teoria. Por isso o debate sobre a prática se esvazia e não avança o suficiente sem que hajam olhos atentos sobre a formação dos professores que a desenvolvem.

É nessa experiência de experiências de ensino que o aluno-mestre irá validar, negar, desenvolver e consolidar os saberes teóricos, transformando-os em experienciais a partir de sua prática e de sua experiência individual e coletiva no ambiente escolar como um todo. Assim, com o passar do tempo, os professores vão incorporando certas habilidades sobre seu saber-fazer e saberser, ou seja, é com a própria experiência que o aluno de outrora, o qual possuía apenas saberes teóricos, aprende a ser professor. (SILVA, 2009, p. 25)

Para tonar-se um sujeito reflexivo que mergulha em sua prática ao passo em que revisita sua formação, o professor precisa ser conduzido, desde o início, ao ato da reflexão e deixe que esta impregne tudo aquilo que deve e precisa fazer para que seus alunos possam aprender a mobilizar uma aprendizagem (TARDIF, 2002). No caso da Geografia, de acordo com Costella (2015), o essencialismo frequente com que é tratado o conhecimento legítimo, do ponto de vista da ciência, gera entraves ao que se nomeia formação cidadã, sobretudo no horizonte das políticas que instituem as formas de fazer-ser dos processos formativos (JACOBI, 2005; MACEDO, 2014). Desse modo, o professor de Geografia carece, desde os saberes de formação aos saberes da experiência construídos no chão da escola, romper com a segregação/separação teoria X prática.

É premente pensar numa escola reflexiva construída por sujeitos reflexivos, na qual uma nova racionalidade opere os processos de ensinar e aprender. Não ensinar o que se deve aprender, mas aprendendo ensinando e ensinando aprendendo, pois a imprevisibilidade do ato educativo requer movimento didático e metodológico que busque não o fechamento das ideias, mas uma contínua busca por uma construção de aprendizagens enfocadas na problematização da vida. Ou seja, "Algo que se paute numa pedagogia do sujeito, do diálogo, cuja aprendizagem seja mediação entre educadores e educandos" (FRANCO; PIMENTA, 2016, p. 541). Esta racionalidade, movida pela comunicação e pela dialogicidade, é o mecanismo de práticas potentes para rasgar os clichês e furar o paradigma estruturante das concepções que norteiam a formação de professores, a prática pedagógica e a própria escola (FERRAÇO, 2015).

Couto (2010) dialoga com o fato de pensar o social com os saberes geográficos, de modo que a rigidez do ensinar algo, ou ensinar a Geografia, não fixe sentidos e significados, tornando o processo de ensino-aprendizagem balizado e dinamizado pela construção de diálogos e não de apenas conceitos. Não desprezando o papel dos conceitos, pois estes permitem ler o mundo e a realidade, porém a lógica que opera estes processos os transforma em instrumentos e não em possibilidades dialógicas. Então, isto significa ler o mundo a partir de conceitos construídos por intermédio de uma ação dialógica, de um ato didático enfocado no diálogo, e cercada pelos elementos realísticos que são vividos e experienciados pelo e no aluno. Significa, de acordo com Franco e Pimenta (2016, p. 541) que "[...] o educador deve ajudar os alunos a questionar sua realidade, problematizá-la e tornar visível o que antes estava oculto, desenvolvendo novos conhecimentos sobre ela."

As questões apontadas são emergenciais, pois a escola carece de ser interlocutora dos processos formadores de mentalidades que subvertem lógicas duras, aceitas como verdades absolutas, imperativas de modos de agir e pensar, além de produtoras de preconceitos. Ou seja, a escola precisa desvirtuar o pensamento dominante (ALARCÃO, 2001; BIZELLI, 2015). E, deste modo, tornar possível a razão sensível, que por sua vez cria as condições necessárias para uma escola reflexiva, para o diálogo de saberes, para uma pedagogia do sujeito, para ações formativas abertas a ruptura com a desigualdade e com os preconceitos. Investir numa escola que faça diferente, ao passo em que faça a diferença (FRAGA, 2015). 
Uma coisa é certa. Urge mudá-la. Não apenas nos currículos que são ministrados, mas na organização disciplina, pedagógica, organizacional. Nos valores e nas relações humanas que nela se vivem. É preciso repensá-la, pensando-a em contexto. Mas não basta que fiquemos no pensar. Depois, é preciso agir para transformá-la. (ALARCÃO, 2001, p. 19)

Este é um debate contínuo e proponente de ações igualmente contínuas. Perpassado pelo diálogo com a sociedade e com seus dilemas, o processo de transformação da escola em uma escola pautada pela reflexividade, como campo de possibilidades mediadoras de ações que congregam saberes, ao invés de diferenciá-los e segrega-los, é uma necessidade de nossos tempos. Romper com as descontinuidades e com as pausas em avanços, enquanto discute-se retrocessos, que é o que temos vivenciado hoje, precisa ser iniciado desde a formação inicial, burlando o discurso que embute um pensamento disciplinar e reprodutivista nos professores em formação (GIROTTO, 2017), conformando-os a uma prática medíocre e silenciadora de saberes outros. E, neste sentido, crê-se ser de grande relevância pensar a ecocidadania como eixo a ser discutido e empregado como uma proposta de reconfiguração das práticas do professor para, de fato, investir-se em uma educação para a cidadania.

ECOCIDADANIA E FORMAÇÃO DE PROFESSORES DE GEOGRAFIA: um campo de possibilidades para uma formação cidadã

Não é de hoje que a formação de professores é uma problemática amplamente pensada nas pesquisas educacionais (SILVA, 2009). Formar professores envolve uma gama de questões que vão desde a elaboração das políticas educacionais até o lugar ocupado pelas práticas pedagógicas dos formadores de professores (LEITE, 2011). Portanto, compreendendo a complexidade que compõe este debate, além da série de peculiaridades e da gama de teorizações atreladas a este campo, nos deteremos a pensar a formação de professores de Geografia a partir de uma perspectiva que nos causa inquietação: a ecocidadania.

Pensar a ecocidadania é pensar em uma ausência de definição e fechamento conceitual, ou seja, é pensar tanto em processo mediático quanto em categoria de análise das práticas que mobilizam os saberes oriundos da interface entre Geografia e Educação Ambiental. Deste modo, não é algo que se possa definir com a clareza necessária para propor formas de ação, mas algo a ser pensado de acordo com as possibilidades existentes nos diferentes lugares, contextos e tempos da escola para, aí sim, formular propostas didáticas que possam ter como base as necessidades formativas que existem naquele cenário em específico. Ou seja, mesmo sabendo que as problemáticas e desafios das escolas tendem a se repetir em diferentes contextos, ainda assim é necessário levar em consideração a multiplicidade de sujeitos e perspectivas que os movem no processo de ensino e aprendizagem (FRANCO; PIMENTA, 2016). Desta feita, a ecocidadania bebe da pedagogia do sujeito, uma vez que para que ela ocorra é necessário ouvi-lo, entende-lo, dialogar com ele para que se possa propor ações que transformem as práticas destes indivíduos sem impor uma aprendizagem que ocorra unilateralmente.

Deste modo, não é objetivo deste texto conceituar a ecocidadania, mas argumentar a partir de elementos que a elaboram como campo de possibilidades para a formulação de uma (eco)formação de professores de Geografia que mobilize os saberes sociais e ambientais, tanto a partir de uma lógica científica quanto a partir de um diálogo com o cotidiano. Processo esse que mergulha na "pedagogia da complexidade ambiental", amplamente debatida por Enrique Leff. Significa dizer que "A pedagogia da complexidade ambiental se constrói, dessa forma, na forja do pensamento do não pensado, do proceder, do que ainda não é, no horizonte de uma transcendência para a outredade e diferença, na transição para a sustentabilidade e justiça (...)" 
(LEFF, 2009, p. 21). Mas se tivermos de abrir espaço para uma tentativa de conceituação, necessária a compreensão daquilo que estamos buscando alcançar, enquanto horizonte teóricometodológico, concordamos com Scherer (2008, p. 63), ao afirmar que

É na dimensão planetária que se passa a estabelecer a nova cidadania: a ecocidadania. A ecocidadania e a cidadania planetária são axiomas que se equivalem e pressupõem o exercício da soclidariedade humana no movimento de unificação da humanidade para manutenção de Gaia.

Deste modo, conforme permanece salientando a autora, a ecocidadania é o próprio movimento de reconstrução do real sentido e significado da cidadania, já desgastada e banalizada, sobretudo por uma ausência de debate sobre esta, que tende a sucatear o potencial socioeducativo que reside em seu cerne. A ecocidadania, ou cidadania planetária, revisa os conceitos e os conteúdos que formam as práticas escolares, revisitando a própria essência humana (solidariedade, pertencimento, afeto, responsabilidade etc.) para justificar a necessidade de reconfiguração do modelo societário em que vivemos, rompendo com o dogmatismo científico e mobilizando uma diversidade de sujeitos e saberes para a construção de um projeto coletivo de sociedade-mundo.

Pode aparentar, à primeira vista, que estamos abordando uma tendência impensável, complexa demais para a formação dos professores, sobretudo em Geografia, mas estamos lidando com um movimento que mergulha em tendências que corrompem o pensar unilateral e a viseira paradigmática, ou seja, provoca o romper com os engessamentos e com a disciplinaridade dos movimentos formativos. Por conseguinte, a formação de professores precisa alimentar-se da complexidade como substância e combustível que gere movimentos que rompam as rotações reprodutivistas e aplicacionistas tão arraigadas às práticas que formam estes sujeitos e que acabam impregnando o chão da escola (SILVA, 2009).

O movimento reflexivo, de acordo com Alarcão (1996), é um desafio até mesmo para aqueles que o tomam como parte de suas práticas. Pensar continuamente o "como?", o "o que?", o "quando?" e o "por quê?" ensinar é um desafio. A autora afirma que o ato reflexivo "é possível, mas difícil. Difícil pela falta de tradição. Difícil, eventualmente, pela falta de condições. Difícil pela exigência de processo de reflexão. Difícil, sobretudo, pela falta de vontade de mudar." (p. 196). Talvez, a afirmativa tenha sido ácida, porém necessária. A reflexão é um caminho de rosas espinhosas, sobretudo pela série de dificuldades que existem e, em muitas situações, independem do professor e de como ele pensa sua prática.

Pensar a prática, tecer uma epistemologia sobre e a partir dela (TARDIF, 2002), requer tempo e espaço, disposição e motivação. No entanto, não se deve ter apego as impossibilidades, marcas de uma educação desvalorizada pelos agentes políticos e geradora de desesperança (CORTELLA, 2014). Por menores que sejam as ações reflexivas dos professores atuantes na escola, ainda assim estas são causadoras de mudanças notoriamente importantes para reconfigurar a escola e propor que esta pense um pouco mais a si própria, modificando o conjunto de práticas que a fazem, ao passo em que modifica sua didática e sua metodologia de ensino, na busca por um multirreferencialidade, ou seja, didáticas e metodologias de ensino que alcance múltiplas formas de construir a aprendizagem (FRANCO; PIMENTA, 2016).

$O$ professor de Geografia precisa mergulhar nesse campo de possibilidades, onde questões emergenciais estão em constante translação entre si, e não girando em torno de si mesmas. A Geografia escolar carece de mediadores de aprendizagem que elaborem suas planificações, suas ações e organizem seus resultados de modo reflexivo. Não uma reflexão que critica e destrói aquilo que deu errado, afinal o "erro" faz parte da aprendizagem, mas repensar os roteiros e não os fixar como prontos e acabados. Acredita-se que a ecocidadania pode contribuir, pois, ao ser mobilizada como perspectiva teórico-prática, incita o pensar, o construir coletivo, o ouvir e o pensar a si próprio enquanto ouço e penso ao outro. A coletividade, o 
aprender coletivo, é uma das características centrais da pedagogia da complexidade ambiental, que vem de Leff (2009), da pedagogia do sujeito, que vem de Freire (1997), e movimenta o processo ecoformativo, tanto na formação inicial de professores quanto na prática pedagógica escolar cotidiana.

A reflexão é nascedouro de um processo vivo, um processo de vida, um saber-vida, que torna possível reconduzir os sujeitos a novas formas de agir, pensar, ser e acontecer no mundo. É deste nascedouro que flui a ecocidadania, cidadania planetária ou, ainda, cidadania ambiental, como aborda Jacobi (2005). O movimento deste processo, desde a formação, tornase espaço para a configuração de uma docência que não se limita e não se apega às impossibilidades e às fronteiras, mas dialoga com as capacidades e habilidades, enxergando os entraves como caminhos para trilhar outras trajetórias.

Desde as epidemias que castram as políticas de currículo e formação, limitando-os a uma única série de elementos discursivos movidos por uma racionalidade tecnicista, até a pandemia da ausência da diversidade de saberes e práticas em sala de aula, é preciso que se pense e se faça outra profissionalização docente em Geografia, desde o início, por entre os cursos de licenciatura, aos espaços das práticas e da continuidade da formação (SILVA, 2009; PEZZATO, 2012). Neste sentido, a ecocidadania torna-se um eixo formador, que tende a mobilizar nestes indivíduos em formação profissional não apenas o apego a uma didática fadada a metodologias de ensino que não dialogam com os sujeitos da aprendizagem escolar, mas fomenta uma ecoformação, ou seja, uma formação que age didaticamente por meio de metodologias ativas que alcancem as múltiplas aprendizagens que ocorrem em sala de aula, provocando um aprender coletivo, um aprender dialógico.

Da crise socioambiental contemporânea surgem novas formas de dialogar e valorizar os saberes negligenciados pela ciência legítima, os quais precisam estar presentes nas tramas formativas e na prática pedagógica escolar em Geografia. O cotidiano, as artes do fazer e os saberes da vida (CERTAU, 1998) necessitam de espaço para estabelecer uma ação mediática situada nas coordenadas da educação do tempo presente, uma educação recivilizatória, uma vez que o projeto de civilização, engendrado pela modernidade, não funcionou, como frisa Morin (2000). A formação dos professores de Geografia precisa pautar-se pela via de acesso aos saberes que dialogam com os sujeitos e sua cotidianidade, humanizando-os ao passo em que os conscientiza de seu papel e lugar no mundo.

A partir destes elementos postos em debate da questão da formação e da prática de professores de Geografia, pensa-se a ecocidadania como trajetória, processo e conjunto de elementos que desvirtua a lógica aplicacionista e conteudista que delimita a Geografia escolar e a torna enfadonha, tanto para quem a ensina quanto para quem a aprende. É preciso ver Geografia no cotidiano (CAVALCANTI, 1998), como realidade vivida e isto só se torna possível quando há espaço para a ocorrência de um processo de mediação que mergulha na Geografia como mecanismo de transformações dos sujeitos, a ler, ser e se reconhecer no lugarterritório-mundo.

Para se pensar em formação cidadã é preciso ir além do posto e disposto pelos saberes que estruturam a formação dos professores de Geografia. Para se pensar em uma educação cidadã é necessário que haja este diálogo com elementos e saberes outros, com o lugar da vida dos indivíduos que estão imersos na cotidianidade social. A ecocidadania, mais uma vez, emerge como possibilidade de traçar uma educação para a cidadania que retrabalhe os sentidos e significados do cotidiano, a partir dos saberes socioambientais, presentes tanto na Geografia escolar quanto na Educação Ambiental (BOTÊLHO, 2017).

Não se tem relatos sobre pesquisas que tenham demonstrado o potencial formativo que a ecocidadania pode mobilizar, ao tornar-se perspectiva e horizonte para as práticas pedagógicas. Botêlho (2017) traz elementos para indicar a ecocidadania como princípio formativo e propositivo para não apenas se repensar e reconfigurar reflexivamente o ensino de 
Geografia e a formação dos sujeitos-formadores que mobilizam esta disciplina escolar, mas uma mudança que vem "de dentro para fora" da escola, alcançando as comunidades, a multiplicidade de relações e sujeitos que pertencem a realidade do lugar, ao cotidiano dos territórios da vida. Como o autor salienta, é preciso descortinar sentido e significados para que a ecocidadania permita a transformação da realidade escolar e social, partindo para metodologias que estimulem o estudo do cotidiano, das problemáticas socioambientais que residem no lugar da vida dos alunos e que afetam a própria escola.

Neste contexto e processo a escola, a educação, é vital para que a ecocidadania se fortaleça, enquanto percurso de emancipação e reconstrução de práticas calcadas ainda no ato memorístico, no enciclopedismo e na transmissão unilateral do saber. É preciso que se entreteçam práticas que partam do pressuposto de fortalecer a consciência sociocrítica, em favor da cidadania, como produto de um ensino enviesado pelo conhecimento espacial e social, tornando possível pensar e agir a partir de uma perspectiva não redutora da relação sociedade-natureza [...] (BOTÊLHO, 2017, p. 77)

A partir disto, consta-se que a formação de professores nos cursos de Geografia deve tornar-se uma seara de diálogos e não de disciplinarização, de mobilização de uma multirreferencialidade didática e metodológica que estruturas didático-metodológicas que normatizam, estruturam e não criam possibilidades formativas capazes de direcionar os professores em formação a vivenciar um processo de diversidades. Sem excluir conceitos e saberes científicos, deve-se haver uma aproximação com formas de ensino que explorem uma Geografia do cotidiano, uma Geografia cidadã que advém da vida dos sujeitos e que se põe como formadora de cidadãos para além das formalidades da lei, mas cidadãos que discernem suas práticas, seus espaços e os outros sujeitos; cidadãos que se enxergam no mundo a partir de seu lugar de vida, agindo reflexivamente sobre ele, transformando-o.

\section{POR UMA TENTATIVA DE CONCLUSÃO}

Como já argumentado anteriormente, não se busca a fixação de um sentido e significado acerca da ecocidadania ou sobre a formação de professores de Geografia, mas alimentar um diálogo tão diverso e tão necessário quanto a própria escola assim é. Deste modo, não há uma conclusão para este texto, assim como não há uma conclusão para os processos educativos. É a continuidade de uma aprendizagem que não se limita a um encerramento do ato de aprender, mas, ao dialogar com a vida, encontra sempre novas maneiras de atingir leituras de mundo.

A tentativa de conclusão é mais uma forma de mostrar a quebra com o processo de domesticação e castração provocado pelas estruturas. A argumentação não se encerra e nem se inicia aqui, mas está em pleno movimento epistemológico sobre a formação dos professores em Geografia, sua prática e a própria escola, que urge pela reflexão como fio condutor de práticas. Práticas inovadoras? O novo é problemático, pois para que ele exista é necessário o velho. A contradição entre novo e velho faz parte deste maniqueísmo que instrumentaliza os saberes, ao invés de coloca-los em constante movimento de aprendizagem.

Como percurso processual de saberes que possa dialogar com outros saberes, outros sujeitos, outros contextos e formas de apreender o mundo, a ecocidadania precisa permear o campo de articulação entre os saberes sociais e ambientais que existem tanto na Geografia escolar quanto na Educação Ambiental. A interface entre estas duas dimensões do processo formativo escolar precisa ter como elementos o diálogo, a coletividade, a reflexão, a diversidade, as múltiplas referências e vida, enquanto palco onde somos todos atores. 
Deste modo, acredita-se que é necessário pensar e propor alternativas didáticometodológicas que tragam a ecocidadania para uma ecoformação dos professores de Geografia. É preciso pensar e propor para o ensino-formação destes professores como algo que não os domestique a um discurso de impossibilidades e improvisos, de produções e aplicações exaustivas; é preciso pensar e propor a pesquisa como via de acesso aos saberes que não estão ditos nos currículos, permitindo o contato com as realidades que se diversificam ao passo em que se tornam complexas; é preciso pensar e propor a extensão, como lugar de práticas que busquem mobilizar a teoria na ação didática, problematizando as realidades de ensino e aprendizagem ao passo em que produz nos sujeitos em formação profissional os saberes experienciais, que criem condições para se pensar em uma epistemologia da prática, uma reflexão sobre a prática.

Formar professores de Geografia para a escola é um desafio, sobretudo diante dos severos ataques sofridos, dos silenciamentos e da transformação sob o rótulo do novo, que tende a invisibilizar a Geografia nos roteiros formativos escolares. Mas não é um desafio impossível de ser burlado. Pelo contrário, é necessário que assim seja e que possa haver uma recontextualização e recondução da docência em Geografia a uma não fixação de saberes, sentidos e significados, centralizando sujeitos e estruturas, mas criando metodologias participativas, dialógicas e ativas que fundam uma educação para a cidadania, de fato e de direito, e se converge com a ecocidadania como princípio, tendência e trajetória formativa necessária para uma educação do tempo presente.

\section{REFERÊNCIAS}

ALARCÃO, I. Ser professor reflexivo. In: ALARCÃO, I. (org.). Formação reflexiva de professores - estratégias de supervisão. Porto: Porto Editora, 1996.

A escola reflexiva. In: ALARCÃO, I. (org.). Escola reflexiva e nova racionalidade. Porto Alegre: Artmed Editora, 2001, p. 15-30.

BIZELLI, J. L. Educação para a cidadania. In: DAVID, M. C. et al (org.). Desafios contemporâneos da educação. São Paulo: Cultura Acadêmica, 2015, p. 19-30.

BOTÊLHO, L. A. V. A ecocidadania como princípio formativo e propósito: diálogos necessários para a construção de uma escola cidadã. Dissertação (Mestrado em Geografia) - Universidade Federal de Pernambuco, Centro de Filosofia e Ciências Humanas, Programa de Pós-graduação em Geografia, Recife, 2017. 195 f.

CAVALCANTI, L. de S. Geografia, escola e construção de conhecimentos. 13. ed. Campinas: Papirus, 1998.

CERTAU, M de. A invenção do cotidiano: artes de fazer. 3. ed. Petrópolis: Editora Vozes, 1998.

CORTELLA, M. S. Educação, escola e docência: novos tempos, novas atitudes. São Paulo: Cortez, 2014.

COSTELLA, R. Z. Para onde foi a geografia que penso ter aprendido. In: CASTROGIOVANNI, A. C. et al (org.). Movimentos no ensinar geografia: rompendo rotações. Porto Alegre: Evangraf, 2015. 
COUTO, M. A. C. Ensinar a Geografia ou ensinar com a Geografia? Das práticas e dos saberes espaciais à construção do conhecimento geográfico na escola. Terra Livre, São Paulo, ano 26, v. $1, \mathrm{n}^{\circ} 34$, p. $109-224,2010$.

FERRAÇO, Carlos Eduardo. Educação-clichê e a necessidade de rasgar sombrinhas... ou sobre violências cotidianas e a necessidade de furar os clichês... In: GARCIA, Regina Leite; ESTEBAN, Maria Teresa; SERPA, Andréa. (Org.) Saberes cotidianos. Rio de Janeiro, Petrópolis: Editora De Petrus, FAPERJ, 2015.

FRAGA, L. A. de. Educação Ambiental e valores: recriando espaço para uma razão sensível. In: BONOTTO, D. M. B.; CARVALHO, M. B. S. da S (Orgs.). Educação ambiental e valores na escola. 1. ed. São Paulo: Cultura Acadêmica, 2016, p. 139-154.

FRANCO, M. A. S.; PIMENTA, S. G. Didática multidimensional: por uma sistematização conceitual. Educação \& Sociedade, Campinas, v. 37, n. 135, p. 539-553, abr-jun, 2016.

FREIRE, P. Pedagogia da esperança: um reencontro com a Pedagogia do oprimido. Rio de Janeiro: Paz e Terra, 1997.

GIROTTO, E. D. Reconhecer os professores e seus saberes: ação política na formação docente em Geografia. Revista de Geografia (Recife), v. 34, n. 1, p. 91-109, 2017.

JACOBI, P. Educação ambiental: o desafio da construção de um pensamento crítico, complexo e reflexivo. Educação e Pesquisa, São Paulo, v. 31, n. 2, p. 233-250, maio/ago. 2005.

LEFF, E. Complexidade, Racionalidade ambiental e Diálogo de saberes. Educação e Realidade, Porto Alegre, v. 34, n. 3, p. 17-24, set./dez. 2009.

LEITE, Y. U. F. O lugar das práticas pedagógicas na formação inicial de professores. São Paulo: Cultura Acadêmica, 2011.

LOUREIRO, C. F. B. (org). Cidadania e meio ambiente. Salvador: Centro de Recursos Ambientais, 2003. 168p.

MACEDO, E. Currículo, cultura e diferença. In: LOPES, A.; DE ALBA, A. Diálogos curriculares entre Brasil e México. Rio de Janeiro: Eduerj, 2014, p. 83-101.

MORIN, E. Sete saberes necessários à educação do futuro. 2. ed. São Paulo: Cortez, 2000.

PEZZATO, J. P. Formação docente e geografia escolar: um estudo de caso entre Brasil e Espanha. São Paulo: Cultura Acadêmica, 2012.

SILVA, M. da. Complexidade da formação de professores: saberes teóricos e saberes práticos. São Paulo: Cultura Acadêmica, 2009.

SCHERER, M. Ambiente e Cidadania: estudo sobre a ação do estado democrático de direito na inclusão social e na sustentabilidade. 2008.167 p. Dissertação (Mestrado em Ambiente e Desenvolvimento) - Programa de Pós-Graduação em Ambiente e Desenvolvimento, Centro Universitário Univates, Lajeado, 2008. 
SOFFIATI, A. Fundamentos filosóficos e históricos para o exercício da ecocidadania e da ecoeducação. In: LOUREIRO, F. B.; LAYARARGUES, P. P.; CASTRO, R. S. de (orgs.). Educação ambiental: repensando o espaço do cidadão. 4. ed. São Paulo: Cortez Editora, 2008. p. 2368.

TARDIF. M. Saberes docentes e formação profissional. 4. ed. Petrópolis: Vozes, 2002. 